DOI: 10.12731/2658-4034-2021-12-2-39-52

УДК 378.046.4:372.881.161.1

\title{
РАЗРАБОТКА МОДУЛЯ \\ ПРОГРАММЫ ПОВЫШЕНИЯ КВАЛИФИКАЦИИ ПРЕПОДАВАТЕЛЕЙ-СЛОВЕСНИКОВ «ФОРМИРОВАНИЕ АКТИВНОГО СЛОВАРЯ ПРОФЕССИИ У СТУДЕНТОВ КАК СРЕДСТВО ПОВЫШЕНИЯ РЕЧЕВОЙ ПРОФЕССИОНАЛЬНОЙ КУЛЬТУРЫ»
}

\section{Шонтукова И.В.}

Предметом представленной работы является процесс повышения квалификации педагогов-словесников в системе среднего профессионального образования.

Цель статьи - разработать и дать содержательную характеристику модулю курсов повышения квалификации, посвященному формированию речевой профессиональной культуры студентов.

В проиессе работы над статьей использовались такие методы, как анализ источников и моделирование.

Результатом работы является разработанный модуль дополнительной профессиональной программы (повыления квалификации) по формированию активного словаря профессии у студентов.

Область применения результатов - система дополнительного профессионального образования. Программа и материаль модуля могут применяться в построении дополнительных профессиональных программ (повышения квалификации) для преподавателей русского языка и литературы, работающих в системе профессионального образования.

Основные выводы статьи заключаются в тезисах о том, что формирование активного словаря профессии является частью общей профессиональной культуры будущих специалистов и требует системного подхода в подготовке преподавателей-словесников в процессе повышения их квалификащии. 
Ключевые слова: активный словарь профессии; повышение квалификачии педагогов; дополнительные профессиональные программы.

\section{DEVELOPMENT}

\section{OF THE MODULE OF THE PROGRAMME OF TRAINING OF TEACHERS-PHILOLOGISTS “, THE FORMATION OF AN ACTIVE VOCABULARY OF THE PROFESSION FROM STUDENTS AS A MEANS OF ENHANCING THE PROFESSIONAL CULTURE OF SPEECH»}

\section{Shontukova I.V.}

The subject of the present work is the process of professional development of teachers of literature in the system of secondary vocational education.

The purpose of the article is to develop and give a meaningful description of the module of advanced training courses dedicated to the formation of students 'speech professional culture.

In the process of working on the article, such methods as source analysis and modeling were used.

The result of the work is the developed module of the additional professional program (advanced training) for the formation of an active vocabulary of the profession among students.

The scope of application of the results is the system of additional professional education. The program and the materials of the module can be used in the construction of additional professional programs (advanced training) for teachers of Russian language and literature working in the system of professional education.

The main conclusions of the article are the theses that the formation of an active vocabulary of the profession is part of the general professional culture of future specialists and requires a systematic approach to the training of teachers of words in the process of improving their skills.

Keywords: active vocabulary of the profession; professional development of teachers; additional professional programs. 


\section{Введение}

Процесс подготовки студентов в системе среднего профессионального образования в последние годы актуализировался повышенным общественным запросом на специалистов среднего звена. Это нашло отражение и во вхождении России в международное движение WorldSkills, и в принятии новых Федеральных государственных образовательных стандартов среднего профессионального образования, требующих введения новой формы государственной итоговой аттестации - демонстрационного экзамена, и в разработке федерального проекта «Молодые профессионалы» национального проекта «Образование».

Овладение профессией будущими специалистами тем не менее осуществляется как многоцелевой процесс. Одним из факторов погружения в профессиональное поле студентов является освоение ими понятийного аппарата изучаемых учебных дисциплин. Эта задача выходит как на преподавателей специальных и общепрофессиональных дисциплин, так и на преподавателей-словесников. Именно роли последних в формировании речевой профессиональной культуры будущих специалистов хотелось бы уделить особое внимание, и отдельно отметить значение системы повышения квалификации педагогов-словесников в формировании их профессиональных компетенций по работе с понятийным аппаратом будущей профессии при обучении студентов.

\section{Обзор литературы}

Изучение источников позволяет рассмотреть поднимаемую в статье проблему с двух сторон: формирование активного профессионального словаря у студентов профессиональных образовательных организаций и совершенствование профессиональных компетенций педагогов-словесников, работающих в системе СПО, в процессе повышения квалификации.

Работа по освоению студентами языка их будущей профессии является очень важной составляющей их общепрофессиональной подготовки. Ключевым моментом здесь видится постоянное попол- 
нение профессионального словаря, т.е. овладение профессиональной лексикой, терминологией. Важную роль данной работы отмечают Малая Е.В. [4], Мкртчян Г.А. [5], Тарханова С.В. [10], Шонтукова И.В. [13], Шубкина О.Ю. [14]. Но если Мкртчян Г.А. и Шонтукова И.В. делают акцент именно на лексической составляющей и технологиях пополнения активного словаря производной лексикой, то Шубкина О.Ю. и Тарханова С.В. обращают особое внимание на коммуникативную сторону формирования речевой профессиональной культуры студентов, а Малая Е.В. рассматривает данную проблему в контексте создания необходимых педагогических условий, в ряду которых стоит формирование особого медиапространства образовательной организации.

Эффективному решению проблемы формирования активного словаря профессии может способствовать овладение педагогамисловесниками компетенциями по системному погружению студентов в язык профессии, терминологию и профессиональную лексику. Данные компетенции могут быть развиты в процессе обучения педагогов по дополнительным профессиональным программам (повышения квалификации).

Важность постоянного совершенствования профессиональных компетенций педагогов отмечается многими как отечественными, так и зарубежными авторами. В частности на этот вопрос направлены исследования Беланже П. [1], Бемера М. [2], Джемилевой Н.Н. [3], Ройтблата О.В. [9], Феймана-Немсера С. и Нормана П.Дж. [12], Чьют X. [15].

В то же время сам процесс повышения квалификации педагогов требует постоянного обновления, приобщения к новым педагогическим технологиям, и должен носить опережающий характер. На эту необходимость также указывают работы Муштавинской И.В. [6], Рытова А.И. [8].

При этом отдельной строкой хочется отметить работы, посвященные проблеме повышения квалификации педагогов, работающих в системе среднего профессионального образования [7], [11], [16]. В этом ряду особого внимания заслуживает работа Наумовой С.И., 
представляющая модель повышения квалификации и профессиональной переподготовки преподавателей русского языка и литературы профессиональных образовательных организаций, реализующих образовательные программы СПО [7].

\section{Постановка задачи}

Анализ источников и личный педагогический опыт автора позволили сформулировать ряд задач для развития профессиональных компетенций педагогов-словесников в системе повышения квалификации.

Во-первых, нам видится необходимым вывести процесс обучения студентов профессиональной лексике и формирования речевой профессиональной культуры будущих специалистов в целенаправленную деятельность.

Во вторых, необходимо развивать у педагогов-словесников, работающих в системе СПО, компетенции по формированию у студентов активного словаря профессии и профессиональной речевой культуры.

Все это возможно осуществить в процессе повышения квалификации педагогов при условии разработки модуля дополнительной профессиональной программы, направленного на решение обозначенных выше задач.

\section{Описание исследования}

В целях решения обозначенных выше задач автором был разработан учебный модуль дополнительной профессиональной программы (повышения квалификации) для педагогов-словесников, работающих в образовательных организациях среднего профессионального образования «Формирование активного словаря профессии у студентов как средство повышения речевой профессиональной культуры». Формат и алгоритм построения модуля во многом были определены научно-практическим опытом работы автора как в системе среднего профессионального образования, так и в системе дополнительного профессионального образования. Модуль стал частью дополнитель- 
ной профессиональной программы (повышения квалификации) для преподавателей русского языка и литературы средний профессиональных образовательных учреждений «Особенности преподавания русского языка и литературы в учреждения среднего профессионального образования», разработанной автором статьи.

В процессе разработки модуля были выделены три основных направления: лексический, текстологический и технологический. Первое направление имеет целью погружение в вопросы формирования специальной лексики и терминологии профессий. Второе организует изучение терминов и специальной лексики через работу со специальными текстами. Третье ставит целью освоение технологии построения производных терминов и обогащения благодаря этому активного профессионального словаря.

Таким образом, в модуль были включены три темы, организующие работу педагогов-словесников в теоретическом и практическом ключе.

Тема 1. Терминологическая лексика - основа профессионального языка.

Теоретическая часть: Пути появления терминов в русском языке. Основные группы терминов: общенаучные, общетехнические, общекультуроведческие, специальные (по отраслям). Терминологические словари и их применение на занятиях по русскому языку и культуре речи в образовательных организациях, реализующих программы среднего профессионального образования.

Практическая часть: Работа преподавателей-словесников по составлению словаря профессии для студентов выбранной специальности. Результатом данной работы должен стать прежде всего перечень специальных слов, активно использующихся в той или иной профессиональной деятельности, для того, чтобы в дальнейшем в работе со студентами педагоги могли отрабатывать понятийный аппарат через составление рабочих толковых словарей.

Тема 2. Специальный текст как ресурс пополнения активного словаря студентов.

Теоретическая часть: Стилистические особенности и жанровое разнообразие специальных текстов. Текст энциклопедической статьи, 
научной, научно-популярной статьи, учебника и учебного пособия. Виды учебной работы со специальным текстом: лингвистический анализ, смысловое чтение, диктанты (выборочные и контрольные), изложения, рецензии, реферирование и др.

Практическая часть: Работа по анализу источников, содержащих специальные тексты. Составление подборки специальных текстов для студентов выбранной специальности. Конструирование заданий для студентов на основе выбранных текстов. Результатом данной работы должна стать подборка специальных текстов и практических заданий для студентов, что в итоге может лечь в основу дидактического пособия.

Тема 3. Пополнение активного словаря студентов через построение словообразовательных моделей производных терминов.

Теоретическая часть: Описание технологии построения словообразовательных моделей производных слов. Наиболее продуктивные модели, используемые в построении производных терминов: суффиксальные существительные с суффиксами лица, суффиксальные прилагательные, суффиксальные и префиксальные глаголы, сложные слова и др.

Практическая часть: Практика построения в рамках представленной технологии производных терминов из списков, выбранных в рамках освоения первой темы. Результатом данной работы должно стать погружение педагогов в технологию построения словообразовательных моделей производных слов и введение данной технологии в свою педагогическую практику.

В качестве примера можно привести работу по формированию активного профессионального словаря у студентов-дизайнеров.

Например, при отборе профессиональной лексики дизайна выделяется группа общедизайнерских терминов, к которым можно отнести следующие: абрис, адаптация, аксонометрия, ансамбль, антропометрия, ассортимент, Баухауз, бионика, Веркбунд, ВНИИТЭ, Вхутемас, выразительность, дизайн, дизайнер, золотое сечение, ИКСИД, инженерная психология, интерьер, информативность, клаузура, комплект, компоновка, лаконизм, лессировка, макет, макетирование, массовое 
(производство), масштаб, масштабность, мода, модель, моделирование, моделировка, морфология, набор (предметов), номенклатура, нюанс, объект, оболочка, оргстекло, опытный образец (изделия), отделка, оценка качества (изделия), перспектива, потребительский, проект, проектирование, проекция, промышленный образец, пропорция, пропорциональность, пропорционирование, прототип (изделия), рабочее место, соразмерность, социально-экономические (требования), структура, текстура, тектоника, техническая эстетика, украшательство, унификация, утилитарность, фактура, чертеж, шаблон, экстерьер, эргономика, эскиз, эскизирование, эффективность и др.

Определившись с данным перечнем терминов в процессе повышения квалификации, преподаватели могут на занятиях со студентами формировать токовый словарь из приведенного перечня.

Следующий этап работы - выделение терминов в специальных текстах и работа с разными видами текстов. Здесь можно использовать подборки специальных журналов, поскольку в них тексты, как правило, имеют более адаптированный к живой речи стиль и легче воспринимаются студентами.

На первом этапе работы с текстом можно предлагать задания типа:

1) Выпишите из текста слова-термины, разделить их по происхождению (заимствованные, исконно русские). Определить, каких терминов больше.

2) Выпишите из текста термины иноязычного происхождения. При помощи словаря иностранных слов определить, из какого языка данный термин заимствован и что он обозначает.

3) Выпишите из текста термины русского происхождения. При помощи толкового словаря определить значение, относящееся к данному термину (для многозначных слов).

Погружение студентов в технологию построения словообразовательных моделей производных слов требует более длительной и системной работы, направленной не только на освоение алгоритма словомоделирования [13, 90-96], но и формирования культуры работы со словарями: словообразовательным, толковым, терминологическим, энциклопедическим. 
При этом можно выделить наиболее продуктивные модели формирования производных терминов, к тором, в частности, относятся суффиксальные и сложные существительные, суффиксальные прилагательные, суффиксальные глаголы.

В качестве примера заданий на комплексную работу можно привести следующее:

\section{Упражнение 1.}

1. Выпишите из текста термины и профессиональные слова. 2. Определите их принадлежность клексико-семантическим группам (научные, технические, искусствоведческие и т.п.). 3. Разделите их по производности-непроизводности. 4. Постройте словообразовательные модели производньх терминов.

Компьютерная культура, информационная технология - эти понятия уже прочно вошли в нашу жизнь. Компьютер становится помощником врача и министра, строителя и бухгалтера, физика и переводчика. Но формировать мышление специалистов, психологически готовых к общению с новой технологией, к жизни в новом информационном обществе необходимо с детства. Как показывает зарубежный и отечественный опыт, компьютерная техника может эффективно выполнять роль нового средства обучения, диагностики и разностороннего развития человека, начиная уже с дошкольного возраста.

Важная роль в проектировании оптимальных форм организации игровой деятельности дошкольников с компьютерами должна отводиться эргономике, цель которой состоит в оптимизации предметного содержания, орудий и условий развивающей игровой деятельности. В задачи эргономики «входит разработка методов системного анализа и проектирования целесообразных вариантов человеческой деятельности, её внешних средств и внутренних способов, методов учёта многообразных человеческих факторов при модернизации действующей и создании новой техники (и технологии обучения. Ю.Г.), а также соответствующих условий деятельности».

Как показал первый опыт использования компьютера в дошкольных учреждениях, новая информационная технология уже 
на дошкольном уровне образования может внести существенные позитивные перемены в процессе не только интеллектуального, но и нравственного, эстетического, а при использовании специальных компьютероуправляемых приспособлений и физического развития детей. При этом, как отмечают и советские, и зарубежные исследователи, у детей наблюдается достаточно высокая мотивация в процессе компьютерных игр. Важно отметить, что такая мотивация сохраняется не только в так называемых «коммерческих», но и в развивающих играх конструктивного, исследовательского, сюжетного, поискового характера. Специально разрабатываемые развивающие экологические компьютерные игры способствуют познанию детьми фундаментальных законов природы, неразрывной связи человека с окружающей природой, пониманию роли компьютера и других технических средств в жизни общества.

(Горвиц Ю.М. Персональные компьютеры для детей. Эргономический аспект. «Техническая эстетика», №2, 1990)

\section{Заключение}

Обобщая всё вышесказанное, можно сформулировать следующие заключительные тезисы:

1. Работу по аспектизации изучения профессиональной лексики студентами средних профессиональных образовательных организаций необходимо выводить на отдельный системный уровень.

2. Развитие компетенции педагога-словесника по формированию активного словаря профессии будущих специалистов может стать частью дополнительной профессиональной программы (повышения квалификации) в качестве учебного модуля.

3. В построения модуля программы курсов повышения квалификации по работе с активным словарем студентов можно выделить три основных направления: составление активного терминологического словаря будущей профессии; работа со специальным текстом на занятиях русского языка в учреждениях СПО; освоение технологии построения производных слов как средство пополнения профессионального словаря обучающихся. 


\section{Список литературы}

1. Беланже П. Образование взрослых в промышленно развитых странах // Перспективы. Вопросы образования. ЮНЕСКО. 1992. № 4. С.13-23.

2. Böhmer M. Zentrale und dezentrale Lehrerfortbildung: Entwicklung, Strukturen und Innovationen. Weinheim und Basel: Beltz, 1983. $113 \mathrm{s.}$

3. Джемилева Н.Н. Сравнительный анализ повышения квалификации учителей за рубежом // Ярославский педагогический вестник. 2011. №1, Том II (Психолого-педагогические науки). С. 209-213.

4. Малая Е. В. Педагогические условия формирования речевой культуры будущих специалистов сферы образования в медиапространстве вуза // Научно-методический электронный журнал «Концепт». 2017. T. 2. C. 433-437. http://e-koncept.ru/2017/570085.htm

5. Мкртчян Г.А. Вопросы методики обучения специальной лексике на уроках русского языка в СПТУ. Ереван: Луйс, 1990. 197 с.

6. Муштавинская И.В. Современные подходы к повышению квалификации: рефлексивные технологии // Вестник Нижегородского университета им. Н. И. Лобачевского. 2011. № 4 (1). С. 25-30. http:// www.vestnik.unn.ru/ru/nomera?anum $=3981$

7. Наумова С.И. Модель повышения квалификации и профессиональной переподготовки преподавателей русского языка и литературы образовательных организаций, реализующих образовательные программы СПО // Педагогика высшей школы. 2017. № 4 (10). С. 31-35. https://moluch.ru/th/3/archive/72/2774/ (дата обращения: 09.02.2021).

8. Рытов А.И. Концептуальные подходы к повышению квалификации педагогических работников в условиях инновационных преобразований // Новые технологии. 2011, № 1. С. 179-183.

9. Ройтблат О.В. Формальное образование взрослых в системе повышения квалификации средствами неформального образования // Мир науки, культуры, образования. 2009. № 7 (19). С. 211-213.

10. Тарханова С.В. Культурно-речевой аспект формирования коммуникативной-профессиональной культуры будущих специалистов // Вестник Челябинского государственного педагогического университета. 2017. № 8. С. 81-86. http://vestnik-cspu.ru/upload/pdf/ issues/2017/2017_8.pdf 
11. Учебно-методическое обеспечение образовательного процесса среднего профессионального образования: метод. рекомендации / [сост. С.Е. Лузгин]; Саран. кооп. ин-т РУК. Саранск, 2011. 68 c. http://13.ruc.su/ upload/medialibrary/4a8/wsww\%20eepsumufzdwd-soeqxsrmjljupszmlvjqayiu\%20\%20kcakgwnylrpikgvuseohxo\%20uijdyk\%20chemkfxqbkpnce.pdf

12. Фейман-Немсер С., Норман П. Дж. Педагогическое образование: от начальной подготовки к непрерывному профессиональному развитию // Moon B., Ben-Peretz M., Brown S. A. Routledge International Companion to Education. Лондон: Routledge, 2000. С. 732-755.

13. Шонтукова И.В. Изучение профессиональной лексики дизайна на основе инварианта CT. Saarbrücken, Deutschland / Германия: LAP Lambert Academic Publishing, 2013. 169c.

14. Шубкина О.Ю. Формирование коммуникативной компетентности студентов в образовательном процессе технического вуза // Фундаментальные исследования. 2014. № 8-5. С. 1206-1210. https://www. fundamental-research.ru/ru/article/view?id=34744

15. Chiout H. Lehrerfortbildung in England, Schweden und Dänemark: Versuch eines Vergleichs // Zeitschrift für Pädagogik. 1982. H. 6. S. 911-934. https://www.pedocs.de/volltexte/2020/14238/pdf/ZfPaed_1982_6_Chiout_Lehrerfortbildung_in_England.pdf

16. Lehrerberuf in Europa: Profil, Tendenzen, Anliegen. Bericht I., Band 3. Brüssel: Eurydice, 2002.

\section{References}

1. Belanzhe P. Perspektivy. Voprosy obrazovaniya. YuNESKO, 1992, no. 4, pp. 13-23.

2. Böhmer M. Zentrale und dezentrale Lehrerfortbildung: Entwicklung, Strukturen und Innovationen. Weinheim und Basel: Beltz, 1983, 113 s.

3. Dzhemileva N.N. Yaroslavskiy pedagogicheskiy vestnik. 2011, vol. II, no. 1, pp. 209-213.

4. Malaya E.V. Nauchno-metodicheskiy elektronnyy zhurnal «Kontsept», 2017, vol. . 2, pp. 433-437. http://e-koncept.ru/2017/570085.htm

5. Mkrtchyan G.A. Voprosy metodiki obucheniya spetsial'noy leksike na urokakh russkogo yazyka $v$ SPTU [Questions of methods of teaching spe- 
cial vocabulary at the lessons of the Russian language in SPTU]. Erevan: Luys, 1990, $197 \mathrm{p}$.

6. Mushtavinskaya I.V. Vestnik Nizhegorodskogo universiteta im. N. I. Lobachevskogo, 2011, no. 4 (1), pp. 25-30. http://www.vestnik.unn.ru/ru/ nomera?anum $=3981$

7. Naumova S.I. Pedagogika vysshey shkoly, 2017, no. № 4 (10), pp. 3135. https://moluch.ru/th/3/archive/72/2774/

8. Rytov A.I. Novye tekhnologii, 2011, no. 1, pp. 179-183.

9. Roytblat O.V. Mir nauki, kul'tury, obrazovaniya, 2009, no. 7 (19), pp. 211-213.

10. Tarkhanova S.V. Vestnik Chelyabinskogo gosudarstvennogo pedagogicheskogo universiteta, 2017, no. 8, pp. 81-86. http://vestnik-cspu.ru/ upload/pdf/issues/2017/2017_8.pdf

11. Uchebno-metodicheskoe obespechenie obrazovatel'nogo protsessa srednego professional'nogo obrazovaniya: metod. rekomendatsii [Educational and methodological support of the educational process of secondary vocational education] / S.E. Luzgin; Saransk, 2011, 68 p. http://13.ruc. su/upload/medialibrary/4a8/wsww\%20eepsumufzdwd-soeqxsrmjljupszmlvjqayiu \%20\%20kcakgwnylrpikgvuseohxo\%20uijdyk\%20chemkfxqbkpnce.pdf

12. Feyman-Nemser S., Norman P. Dzh. Pedagogicheskoe obrazovanie: ot nachal'noy podgotovki $\mathrm{k}$ nepreryvnomu professional'nomu razvitiyu. Moon B., Ben-Peretz M., Brown S. A. Routledge International Companion to Education. London: Routledge, 2000, pp. 732-755.

13. Shontukova I.V. Izuchenie professional'noy leksiki dizayna na osnove invarianta ST [Study of professional design vocabulary based on the ST invariant]. Saarbrücken, Deutschland / Germaniya: LAP Lambert Academic Publishing, 2013, 169 p.

14. Shubkina O.Yu. Fundamental'nye issledovaniya, 2014, no. 8-5, pp. 1206 1210. https://www.fundamental-research.ru/ru/article/view?id=34744

15. Chiout H. Lehrerfortbildung in England, Schweden und Dänemark: Versuch eines Vergleichs. Zeitschrift für Pädagogik, 1982, no. 6, pp. 911-934. https://www.pedocs.de/volltexte/2020/14238/pdf/ZfPaed_1982_6_Chiout_Lehrerfortbildung_in_England.pdf 
16. Lehrerberuf in Europa: Profil, Tendenzen, Anliegen. Bericht I., Band 3. Brüssel: Eurydice, 2002.

\section{ДАННЫЕ ОБ АВТОРЕ}

Шонтукова Ирина Васильевна, заместитель директора, кандидат педагогических наук, доцент

Центр непрерывного повышения профессионального мастерства педагогических работников Минпросвещзения КБР ул. Чернышевского, 226, г. Нальчик, 360004, Российская Федерация shonirina@yandex.ru

\section{DATA ABOUT THE AUTHOR}

Irina V. Shontukova, Deputy Director, Candidate of Pedagogical Sciences, Docent

Center for Continuous Professional Development of Teaching Staff of the Ministry of Education of the Kabardino-Balkar Republic 226, Chernyshevsky Str., Nalchik, 360004, Russian Federation shonirina@yandex.ru ORCID: 0000-0002-7665-7215 